\title{
Chapter 9 \\ Coping Strategies of Migrant Ex-partners. Does Work, Family, or a New Partner Help You Through the Dark Times?
}

\author{
Dimitri Mortelmans, Layla Van den Berg, and Gert Thielemans
}

\begin{abstract}
This study focuses on financial consequences of a separation for migrant ex-partners. International literature on economic consequences has well documented the gender effects in the consequences of splitting up or the differences between former married and cohabiting couples. Building on these insights, this chapter focuses on the heterogeneity in couples in migration status and origin group. Using data from the Belgian Crossroads Bank of Social Security, we look at financial consequences after a break-up for European and non-European ex-partners with a migrant background. Using latent growth modelling for income trajectories of men and women after divorce, we show that migrant background plays a role to a certain extent. Gender effects were large and significant in all subgroups but contrary to our expectations, economically weaker groups show a more modest financial drawback compared to stronger groups. Coping strategies showed patterns that were expected except for returning to the parental home which had a negative influence on the income trajectory. The (weak) economic position of the parents in some migrant group explains this effect.
\end{abstract}

Keywords Divorce $\cdot$ Economic consequences $\cdot$ Migrants · Coping strategies · Register data

\subsection{Introduction}

Despite considerable international differences, women have consistently been shown to be at the economic downside of a divorce (Andreß et al. 2006). Men lose little or no income after divorce while financial losses for women can be substantial. In order to cope with these economic adversities, women can either start working,

D. Mortelmans $(\bowtie) \cdot$ L. Van den Berg $\cdot$ G. Thielemans

University of Antwerp, Antwerp, Belgium

e-mail: Dimitri.Mortelmans@uantwerpen.be; Layla.Vandenberg@uantwerpen.be;

Gert.Thielemans@uantwerpen.be 
increase their working hours (or depend on benefits) or find a new partner (Jansen et al. 2009). We define divorce in this chapter as the dissolution of a household, irrespective of the legal procedure of divorce they might have to go through. As we focus on economic consequences, the moment two partners no longer live together, economies of scale cease to exist and the newly formed households have to deal with the consequences thereof and develop coping strategies in that respect. Although there might exist certain differences in financial consequences between the dissolution of a marriage and that of a legal separation, these are likely to take effect after the legal matters are settled.

As for the first strategy, a positive association between relationship dissolution and employment intensity can be expected. The pecuniary drivers behind this relationship are firstly the loss of household income and secondly the loss of economies of scale resulting from the establishment of smaller households (Couch et al. 2013). As for non-pecuniary benefits, paid employment supposedly acts as a substitute for some of the latent benefits (Stiglbauer and Batinic 2012), which are lost with the end of a relationship such as social contact, sense of self-worth and friendship.

On the partner market, mothers have lower repartnering opportunities due to their care burden. When taking care of (young) children, women are less available on the partner market but they are also far less attractive in the eyes of potential new partners. Alternatively, the increased financial burden for women increases the need for repartnering and therefore might intensify women's search for a new partner. We have shown in earlier research that repartnering outweighs the effect of labour market strategies, especially for mothers (Jansen et al. 2009).

A shortcoming in the existing literature on economic consequences of union dissolution is that most studies do not consider population heterogeneity in migration status and origin group. It is relevant to take this heterogeneity into account given the increasing diversity in most societies and the differences in family patterns, socio-economic position and family attitudes often found among migrant populations. Research indicates that the level of acceptance regarding union dissolution, and particularly divorce, is much lower among some migrant populations. This is particularly true in Moroccan and Turkish migrant communities where divorce is often associated to reduced family honour (Koelet et al. 2009a). If divorce results in the loss of emotional and financial support, it can have important repercussions for the economic consequences of divorce and the kind of coping strategies that are used. The loss of support from community and family-in-law is particularly impactful for migrants who immigrated in the context of marriage to a second generation migrant and often strongly rely on these informal support networks for information and aid.

In addition, non-European first and higher generation migrants in Belgium still experience profound disadvantages in the educational system and on the labour market which means that economic consequences can be harsher and employment as a coping strategy is more difficult to apply. This is particularly true for women with a migrant background. Traditional gender-role expectations and the vulnerable labour market position of these women often result in a higher prevalence of male breadwinner models in couples with a migrant background. Combined with the 
generally younger ages at first union formation, human capital investments that can facilitate post-divorce employment may be limited among migrant women.

Taking migrant populations into account, this chapter looks at three different coping strategies for women: repartnering, returning to the parental home, and increasing one's labour market activities. We assess and compare the efficiency of these coping strategies in regaining their predivorce income levels.

\subsection{Background}

\subsubsection{Financial Consequences and Relationship Dissolution}

While there is considerable consensus in the literature that relationship dissolution is usually associated with a loss of financial wellbeing, the question of who suffers most or even if all involved do suffer, is still under much debate. The drop in financial resources is theoretically attributed to the loss of a partner's income on the one hand, and the loss of economies of scale on the other hand. Divided by gender, women are assumed to lose the most because they are more often working less or not at all, and the additional relative costs of a smaller household. Men are therefore assumed to suffer less, since they usually only incur losses in economies of scale (Couch et al. 2013). Children are more often left under the custody of the female ex-partner, which brings extra costs. On the other hand, men are more often required to pay child support, which decreases their disposable income.

Most previous studies indeed find that women suffer greater financial losses whether in household or per capita income, especially when children are involved (for an overview, see: Andreß et al. 2006). There are however some notable exceptions. McManus and DiPrete (2001) find that in the United States, only men whose pre-dissolution income consisted of less than one fifth of the partner's income, improve their financial situation. However, since the literature on the loss of income convincingly points towards greater losses for women, we firstly hypothesize that there is a gender gap where women lose more financially than men right after divorce independent of migrant background (hypothesis 1).

In addition to the initial gender gap in financial consequences after relationship dissolution, the question remains whether the loss in financial wellbeing is temporary or permanent. Using British data, Fisher and Low (2009) found that women tend to recover financially at around 9 years after divorce, although this is mainly driven by repartnering, rather than increased employment. For the weakest groups, government provided benefits did provide a cushion against the financial downturn. This can be explained firstly by the lower possible fall in household income, but also by eligibility to means-tested benefits. Since men and women with stronger labour market positions generally earn more as a dual-earner couple, the nominal drop in household income is usually larger. As they are less likely to be eligible for meanstested benefits, this would initially result in a proportionally larger drop as well. 
However, they are theoretically more able to increase employment as well as more attractive on the partner market, so they are likely to recover more quickly. Conversely, certain allowance penalties may interfere with the attempt to raise wages for those with weaker labour market positions (Herbst and Kaplan 2016). van Damme (2010) shows that class membership matters and that the income position of the ex-spouse also determines economic consequences after the break-up. All in all, although the decline for economically weaker groups can be expected to be less steep than for the stronger groups, we also expect recovery to be slower.

\subsubsection{Coping Strategies After a Break-Up}

As outlined before, financial losses after relationship dissolution are incurred mainly through two channels: the loss of household income and the loss of economies of scale. The first may be compensated by increasing one's employment, while the second can be offset by for instance starting to live with a new partner or returning to live with parents (Jansen et al. 2009). Previous research has found that repartnering is the most important factor for women in recovering from the negative financial consequences of divorce (Fisher and Low 2009; Jansen et al. 2009). Especially for low-wage workers, additional household income from other adults has been shown to be an effective way of avoiding poverty (Gardiner and Millar 2006). We therefore hypothesize that repartnering increases income after a break-up (hypothesis 2a). Other than living with a new partner in order to compensate for the loss of economies of scale, it is also possible to return to the parental home. Under the assumption that incomes are pooled in this situation, we hypothesize that living with a parent increases the income after a breakup (hypothesis $2 b$ ).

Concerning increased employment, intuitively an increase in working hours should be associated with a rise in household income, even if this increase is modest and relatively lower than the impact of other coping strategies (Fisher and Low 2009; Jansen et al. 2009). This positive association with employment increase and household income constitutes our next hypothesis. Although intuitive, this association is not self-evident. For instance, increased employment could result in the loss of means-tested benefits. If those with lower possible earning profiles choose to increase their employment rather than receiving benefits, for instance to give a signal of self-sufficiency during custody battles, income could possibly decrease as a result. Previous research has shown that possibly for this reason, only a small percentage of low-wage workers use this strategy to avoid poverty (Gardiner and Millar 2006). However, on average, we hypothesise that the relationship is positive, regardless of background (hypothesis 2c). 


\subsubsection{Economic Consequences and Coping Strategies Among Ethnic Minorities}

Research on financial consequences of union dissolution and coping strategies rarely takes into account population heterogeneity with respect to migration background and minority status. Nevertheless, previous studies have shown that couples with a migrant background differ from the majority population with respect to a number of relevant characteristics such as socio-economic position and reliance on informal support networks. Additionally, minority communities are often found to have differing views regarding union dissolution. The growth and diversification of migrant communities in most European countries provides us a with an opportunity to test whether income trajectories and coping strategies after union break-up differ by migrant background. Yet, we should also acknowledge that couples consisting of at least one partner with a migrant background are not a homogenous group. Some migrant populations in Belgium, such as Turkish and Moroccan groups, are characterized by relatively high levels of marriage migration in which a migrant of the second generation marries a partner from the country of origin (Dupont et al. 2017). Contrary to second and later generation migrants, first generation men and women that migrate in the context of marriage migration often lack country-specific human capital such as language, education and employment experience and need to depend heavily on their spouses' relatives and the broader migrant community for support (De Haas 2010; Hernández-Plaza et al. 2006). Given this heterogeneity by generation, we want to pay specific attention to couples resulting from marriage migration when formulating hypotheses on the economic consequences of union dissolution and coping strategies among ethnic minorities. In the next paragraphs, we will stipulate a number of moderating factors that lead us to suspect that migrant background and generation matter in post-relationship income trajectories after union dissolution.

Firstly, extensive research has shown that a large gap in socio-economic status persists between majority and minority populations in Europe. Both first and second generation migrants have been found to have consistently lower employment rates (Heath et al. 2008; Münz 2007). In the Belgian context, persons with a migrant background have been found to experience more difficulties in the educational system and in reaching stable employment and higher income levels (Baert et al. 2016; Corluy et al. 2015; Mussche et al. 2014; Phalet 2007). According to a study by Baert et al. (2016), the gap in education and employment between majority and minority groups is larger for women compared to men indicating that women with a migrant background occupy a particularly vulnerable position. The precarious position of women with a migrant background is amplified by earlier union formation among non-European women (Corijn and Lodewijckx 2009). Young ages at union formation can be accompanied with a more limited investment in human capital such as education and labour market experience when the couple is formed. These dynamics can contribute to the larger prevalence of the male breadwinner model often found among couples with a migrant background. 
Secondly, informal support networks have been found to be of great importance for minority populations. This is certainly the case for recent immigrants who can lean on these support networks for emotional, social and material support (Boyd 1989; De Haas 2010). Informal support networks can also be of particular importance to later generation migrants who wish to marry a partner from the country of origin. In this case, networks provide important sources of information, logistic support and contacts with the country of origin (Lievens 1999). In addition to providing support, these local communities can also enforce cultural expectations regarding family arrangements and sanction behaviour that deviates from the cultural norms (Fernandez and Fogli 2009; Furtado et al. 2013). Especially among non-European minority groups, union dissolution and divorce is met with lower levels of acceptance. A study by Koelet et al. (2009b) shows that maintaining good family relationships and family honour is emphasized in Turkish and Moroccan communities and are threatened by divorce. In contexts where union dissolution is not approved, breaking up a relationship can result in a loss of social and economic support from informal contacts such as family or the broader community. Alternatively, informal networks could also provide a safety net in case of union dissolution and can not only provide emotional and social support but also soften the financial blow by providing opportunities to move in with relatives or increase labour market attachment. This idea is, however, contradicted by a study by Kleinepier et al. (2017) that shows a lower tendency to move back in with parents after union dissolution among second generation men and women compared to Dutch natives. In addition, the options to move in with parents or other relatives after union dissolution are likely to be very limited for first generation migrants.

Given the difficulties in obtaining a better socio-economic position and the possible loss of informal support networks, we expect more negative consequences of relationship dissolution among partners with a migrant background (hypothesis 3a). Since community support may be of greater importance for first generation migrants, investments in human capital in the country of origin is more limited and employment is more often unstable and in lower paid jobs, we expect the strongest financial consequences among men and women of the first generation who migrated in the context of marriage migration (hypothesis $3 b$ ). With respect to the income trajectory after relationship dissolution, we expect recovery to be less steep among ethnic minorities compared to Belgian men and women (hypothesis 4a). Again, this recovery is expected to the weakest among first generation men and women who migrated in the context of marriage migration (hypothesis $4 b$ ).

Regarding the efficiency of coping mechanisms, we do not expect a differing effect of increasing employment on the income trajectory after relationship dissolution (hypothesis 5a). Although increasing employment may be harder to achieve for men and women with a migrant background, the impact should not differ if they succeed. Similarly, we do not expect that repartnering has a differing impact on income trajectories after relationship dissolution for minority and majority populations (hypothesis 5b). With regard to moving in with parents, we expect this strategy to be less efficient for migrant populations (hypothesis $5 \mathrm{c}$ ). Given the more precari- 
ous economic position and greater level of welfare dependency among persons with a migrant background, moving in with parents may not provide a financial advantage for men and women with a migrant background. This hypothesis is supported by a study by Shirahase and Raymo (2014) which finds that a sizeable group of single mothers lives with parents that fall below the poverty line and cannot provide financial support.

\subsection{Data \& Methods}

\subsubsection{Data}

In this study, we used Belgian data from the Data Warehouse on Labor Market and Social Security. This large-scale administrative dataset contains information from nearly all social security agencies in Belgium (e.g., National Office of Social Security, National Employment Office, and the National Institute for Health and Disability Insurance). A sample was drawn consisting of 46,050 households that had experienced the dissolution of their relationship in either 2007, 2008 or 2009. The sample consisted of 21,600 divorced couples and 24,450 formerly unmarried cohabitating couples. The sample was drawn on the (non)-migrant status of one (ex-)partner resulting in 30,000 Belgian sample members, 3000 European women, 6500 European men, 3000 non-European women and 3550 non-European men. In this study, "migrant status" is defined as being from a first, second (parents) or third (grand-parents) generation of migrants according to nationality and country of birth. For Belgian sample members, an additional requirement was added in that the partner of this respondent was also from a non-migrant Belgian background. Recent migration movements are not immediately registered in the Datawarehouse. Since the most recent data in the study was from $2013(t+4$ in the 2009-wave), we assume that we miss a minimum of recent migrants. Illegal migration is not covered by the administrative data and is therefore not included in the models.

No self-employed cases were kept in the analysis as the database contained no reliable information on their income. We also imposed a maximum age of 55 for inclusion in the sample, as older people might face more difficulties in applying the strategies to mitigate the economic consequences of union dissolution, and because they might experience declines in income due to retirement (or early retirement). With these restrictions taken into account, we used data from 42,898 women, of whom $47.3 \%$ were divorced and $52.7 \%$ had previously been living with a partner without being married. We used data from 39,119 men, of whom $48.2 \%$ were divorced and $51.8 \%$ had experienced the dissolution of an unmarried cohabitation. Data were available starting from 1998 but we included data in the models only 2 years before the dissolution up to 4 years after the end of the relationship. The longitudinal structure of the data is illustrated in Fig. 9.1. 


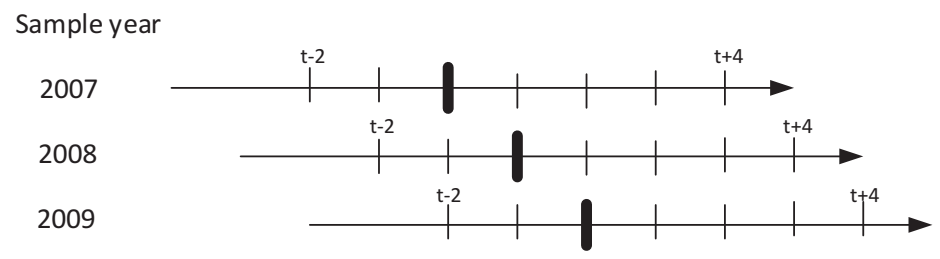

Fig. 9.1 Longitudinal data structure of the study. (Source: Data Warehouse on Labour Market and Social Security)

\subsubsection{Measurements}

The dependent variable was (gross) household income. This included earnings from employment, as well as public transfers because of disability and career interruption for all household members older than 16. Childcare transfers or partner alimony payments are not included in the income data. Since partner alimony is structurally reduced since the law of 2007, only the absence of childcare transfers limit our view on the total income. In the Belgian context, welfare provisions are based on prior labour market experience and household size. There are no specific public subsidies aimed at separated or divorced men and women and immigrants. However, previous studies have shown a higher level of welfare dependency among people with a migrant background (Carpentier et al. 2014). We used the modified equivalence scale developed by the Organization for Economic Cooperation and Development (Förster 2007) to adjust the household-income measures for household composition and household needs. Using this scale, the first member in the household was weighted with a factor of 1 , and other household members of 14 years of age or older with a factor of 0.5 . Children under 14 were weighted with a factor of 0.3 . This equivalence scale has been successfully applied in other studies examining the economic consequences of relationship dissolution (de Regt et al. 2012; van Damme et al. 2009). When modelling income, we need to take the economies of scale into account. All results were dependent on assumptions regarding these economies of scale and, more specifically, on the equivalence scale. For more information about this issue, see Jarvis and Jenkins (1999). We used a different equivalence scale (see: Andreß et al. 2006) as a robustness test and no changes in the results were observed. The income measure was adjusted for inflation. To make the income paths linear and to cope with the skewness of the data, we took the natural logarithm of the adjusted household income.

The following indicators for our independent variables on the three coping mechanisms were used. The increase (or decrease) in labour-market participation was measured categorically. The labour supply of the respondents in the years after the relationship dissolution was compared with their labour supply before the dissolution. People who did not have a paid job before the relationship ended and who started to work afterwards were considered as having increased their labour supply. People who had worked part-time and increased their employment to a fulltime 
position after the dissolution were also considered as having increased their labourmarket participation. Having a parent in the home is self-explanatory. We do not know whether the ex-partners moved in to the home of their parents or in reverse that the parent moved in with the respondent. We only observe co-housing of the ex-partner with (at least) one parent. Re-partnering was defined as living with a new partner (married or not) after the dissolution of the union in question.

All models for Moroccan, Turkish and Southern European respondents contain three dummies representing the ethnic composition of the couple. The reference category in all models is a homogamous couple with both partners stemming from the same generation (and migration background). A first dummy concerns a couple where the man is from the second generation (or later) and the woman has migrated (first generation). The second dummy is the mirror of the first with a man migrating (first generation) and the woman being from second or later generation. The last two dummies concern mixed relationships with the third dummy having a male partner from another origin and the last dummy a female partner of another origin. This other origin could also be a Belgian background. The model of Belgian respondents contains only homogenous Belgian couples (since the mixed relationship are included in the Moroccan, Turkish and South European models).

In the analyses, we controlled for a number of background variables. These variables concerned the differences between formerly married and cohabiting partners, female relative share of the gross household income, welfare dependency, age (mean-centered plus age squared), being at work (time varying dummy) and working part-time (time varying dummy), region (Flanders, Wallonia, Brussels Capital Region), and household income (inflation corrected and OECD modified) 1 year before the dissolution. The control variable "having young children in the household' measured the presence of children younger than 3 (time varying). All models were also estimated separately for men and women.

\subsubsection{Analytical Strategy}

The register data allowed us to use a longitudinal design. Cross-sectional data would not be sufficient for estimating the consequences of relationship dissolution. It would also be impossible to judge the influence of coping mechanisms after divorce when timing of divorce and subsequent income trajectories could not be used. Many people remarry or enter another cohabitation union after the dissolution of a relationship. It is possible that the group of people who remained single constituted a selective sub-sample of all people who had experienced the dissolution of a partnership. The same goes for the return to the parental home. In the past, we have used survey panel data for our analyses (Jansen et al. 2009) but issues of non-response and selective attrition from the initial sample are always present in these cases. Also the number of divorces is sometimes a worry when using survey data (e.g. Andreß et al. 2006) or the number of respondents with a migrant background, let alone the combination of these two. The register sample allows to include thousands of 
relationship dissolutions in our models. This large sample has several advantages. First, the statistical power is greater, making parameter estimates more robust. Second, it allows us to examine the financial consequences of relationship dissolution in more detail (e.g., focusing on the dissolution of cohabitation unions among groups with a migrant background). As far as we know, no other study has ever combined financial trajectories after dissolution with a focus on respondents having a migrant background.

We use growth models (Singer and Willett 2003) to model the economic consequences of relationship dissolution. Longitudinal data can be seen as multileveldata, in which repeated measurements are nested within persons (Hox 2002). A growth model is a two-level model, with time (in years) on the first level and individual characteristics on the second. Using multilevel analysis is advantageous because it does not lean on the assumption of independence of observations and it gives more accurate estimates of the standard errors. Due to the sample size of the study, we only consider a significance level of $p<0.001$.

In order to model the trajectory of income before, during, and after the break, we use three time variables (splines), referred to as "Pre-split-growth", "Split relation" and "Post-split growth". In the null random intercept model, i.e., the model without any covariates except for the time variables (see Table 9.2), the intercept estimates the income measure at time 0 , the year before the actual dissolution. At this time point the three period variables are assigned the value 0 . The estimate for the random slope associated with the pre-split growth indicates the linear trend in adjusted household income up until the year before the dissolution. Afterwards, this variable is assigned the value 0 . Analogous the slope associated with the third period assesses the pace of income recovery after partnership dissolution, which is assumed to evolve linearly with time. This variable is equal to 0 up to $t=2$ and is allowed to vary from $t=2$ onwards. Contrary to the first and third splines, the "split relation" variable is essentially a dummy variable that is assigned the value 1 at the event of separation. Because the other time variables are assigned the value 0 in the year of separation, this slope assesses the impact of the partnership dissolution on the adjusted income level. It continues to have the value 1 during the whole "recovery" period though. In this way, we model the instantaneous impact of repartnering, (re-) employment and other covariates on the needs-adjusted income level in the years following the separation (in the split-separation), as well as the impact of these covariates on the linear growth rate. In order to achieve this, we add interaction terms between the explanatory variables and period 2 and period 3 . Because we are not interested in explaining the pre-divorce growth, no interaction terms will be added with the pre-split growth.

The postulated model can be written as follows:

$$
\begin{array}{ccccc}
\text { Level } & 1: \text { adj } & H H-\text { income }=\pi_{0 i j}+\pi_{1 i j} & \text { Pre-split growth } \\
& +\pi_{2 i j} & \text { Split relation }+\pi_{3 i j} & \text { Post }- \text { split } & \text { growth }+\varepsilon_{i j k}
\end{array}
$$




$$
\begin{aligned}
\pi_{0 i j} & =\gamma_{00 j}+\zeta_{0 i j} \\
\text { Level 2: } \pi_{1 i j} & =\gamma_{10 j}+\zeta_{1 i j} \\
\pi_{2 i j} & =\gamma_{20 j}+\zeta_{2 i j} \\
\pi_{3 i j} & =\gamma_{30 j}+\zeta_{3 i j}
\end{aligned}
$$

The $\varepsilon$, $\zeta$ 's and $\xi$ 's represent respectively the within-person residual and the between-person within-country residuals. The error (co)variances are all estimated in the models. The so-called unconditional growth model will be extended by introducing time-constant as well as time-varying covariates into the level 1 and level 2 sub models.

\subsection{Results}

\subsubsection{Descriptive}

In Fig. 9.2, we show the distribution of mean adjusted household incomes for women across all groups in our sample. We do not show the graphs for men as these are relatively flat and differences between groups are limited. These results clearly reflect a drop in income after the dissolution that is consistent with earlier research. On average, the financial conditions of women with a migrant background are, overall, more negative compared to Belgian women. Belgian women earn more than women with a different background. Especially compared to women in a homogeneous migrant family, we see that the income trajectory on average is $11 \%$ higher for women in a homogenous Belgian couple. The relative income drop due to the break-up ( $\mathrm{t}-1$ to $\mathrm{t}$ ) is different across all groups and ranges between 16\% (mixed relation with Moroccan man) and 29\% (mixed relation with Moroccan woman).

The compositional differences between all four nationalities (from the respondents perspective) can be found in Table 9.1. As we take the year of sampling $(\mathrm{t}-1)$ in the table, we have an equal amount of men and women at the start of the trajectories. We see that the composition of the couples differs substantially between the Southern European couples on the one hand and the Moroccans and Turks on the other. For Southern European couples, homogeneity in the couple is hardly present. Most couples are of a mixed nature (predominantly with a Belgian partner). For Moroccan and Turkish couples, homogeneity within the couple prevails. For Turkish couples, most couple are also from the same generation. For both communities, new migration consists predominantly of men migrating to Belgium but the amount is still limited to one in three. In the Moroccan community, we see greater signs of 

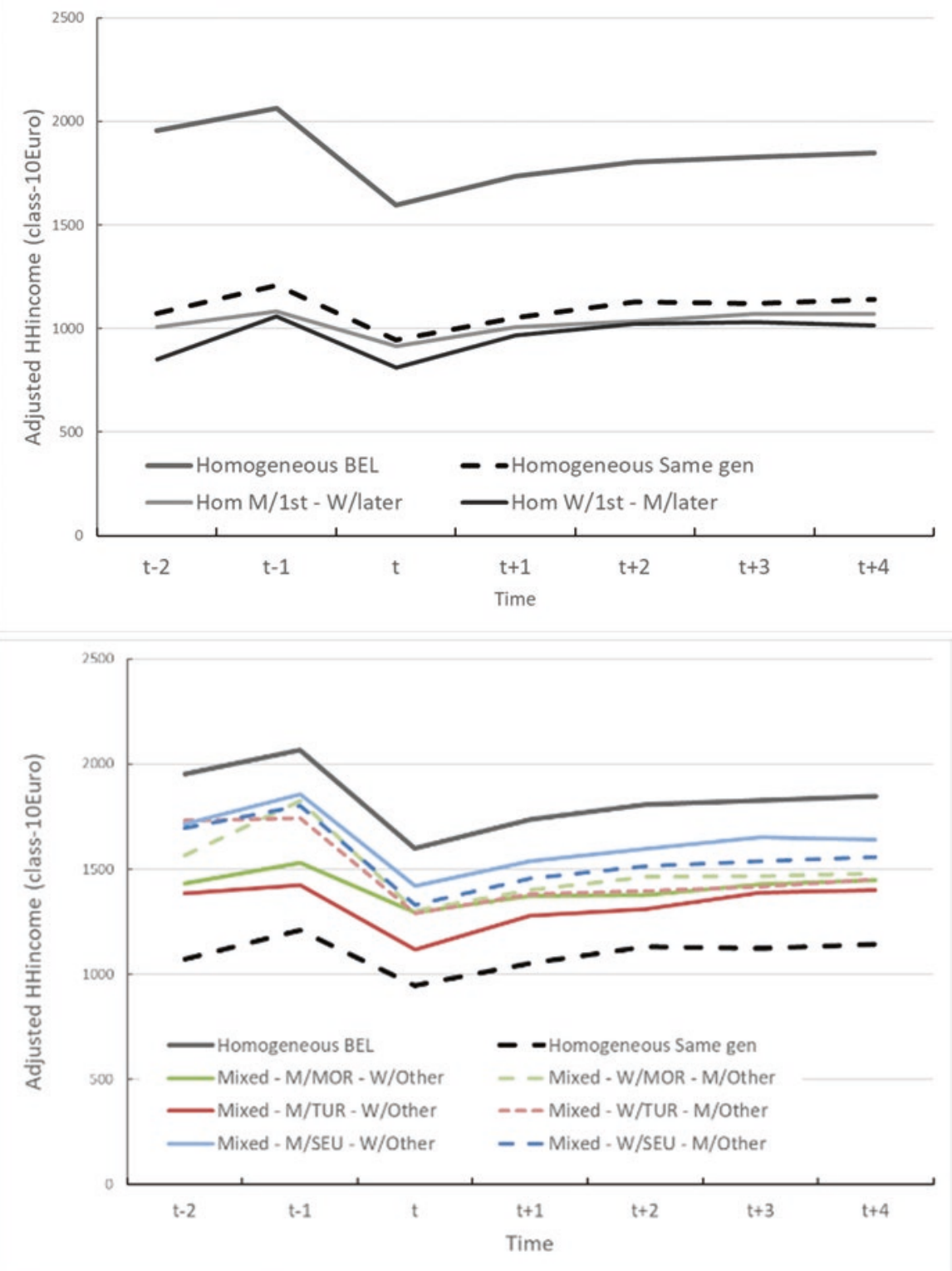

Fig. 9.2 Income trajectories of women, according to composition of the initial family 
9 Coping Strategies of Migrant Ex-partners. Does Work, Family, or a New Partner...

Table 9.1 Frequencies (column percentages) for main variables in year $t-1$

\begin{tabular}{|c|c|c|c|c|}
\hline & Belgian & $\begin{array}{l}\text { Southern } \\
\text { European }\end{array}$ & Moroccan & Turkish \\
\hline $\mathrm{N}$ persons $(\mathrm{t}-1)$ & 72,340 & 6790 & 9420 & 4302 \\
\hline $\mathrm{N}$ couple-years & 795,740 & 74,690 & 74,690 & 103,620 \\
\hline \multicolumn{5}{|l|}{ Gender $(\mathrm{t}-1)$} \\
\hline Men & $36,168(50 \%)$ & $3395(50 \%)$ & $4710(50 \%)$ & $2151(50 \%)$ \\
\hline Women & $36,172(50 \%)$ & $3395(50 \%)$ & $4710(50 \%)$ & $2151(50 \%)$ \\
\hline \multicolumn{5}{|l|}{ Ethnic composition $(\mathrm{t}-1)$} \\
\hline Homogamous: same gen. & $49,214(68 \%)$ & $810(12 \%)$ & $2474(26 \%)$ & $1632(38 \%)$ \\
\hline $\begin{array}{l}\text { Homogamous: woman } 2 G \text {, } \\
\text { man } 1 G\end{array}$ & & $160(2 \%)$ & $2140(23 \%)$ & $1060(25 \%)$ \\
\hline $\begin{array}{l}\text { Homogamous: } \operatorname{man} 2 G \\
\text { woman } 1 G\end{array}$ & & $96(1 \%)$ & $1208(13 \%)$ & $440(10 \%)$ \\
\hline Mixed: woman other origin & $11,924(16 \%)$ & $3046(45 \%)$ & $1942(21 \%)$ & $586(14 \%)$ \\
\hline Mixed: man other origin & $11,198(16 \%)$ & $2678(40 \%)$ & $1656(17 \%)$ & $584(14 \%)$ \\
\hline \multicolumn{5}{|c|}{ Relative share of female income $(\mathrm{t}-1)$} \\
\hline $0 \%$ & $10,076(14 \%)$ & $1098(16 \%)$ & $1758(19 \%)$ & $878(20 \%)$ \\
\hline $1-19 \%$ & $6806(9 \%)$ & $722(11 \%)$ & $1156(12 \%)$ & $492(11 \%)$ \\
\hline $20-39 \%$ & $17,985(25 \%)$ & $1576(23 \%)$ & $1852(20 \%)$ & $912(21 \%)$ \\
\hline $40-59 \%$ & $21,408(30 \%)$ & $1826(27 \%)$ & $1712(18 \%)$ & $722(17 \%)$ \\
\hline $60-79 \%$ & $5483(8 \%)$ & $602(9 \%)$ & $984(10 \%)$ & $368(9 \%)$ \\
\hline $80-100 \%$ & $10,582(15 \%)$ & $966(14 \%)$ & $1958(21 \%)$ & $930(22 \%)$ \\
\hline \multicolumn{5}{|l|}{ Welfare state dependency $(\mathrm{t}-1)$} \\
\hline $0 \%$ & $44,462(61 \%)$ & $3372(50 \%)$ & $2850(30 \%)$ & $1019(24 \%)$ \\
\hline $1-19 \%$ & $17,284(24 \%)$ & $1606(24 \%)$ & $1786(19 \%)$ & $888(21 \%)$ \\
\hline $20-39 \%$ & $4044(6 \%)$ & $606(9 \%)$ & $1138(12 \%)$ & $598(14 \%)$ \\
\hline $40-59 \%$ & $1531(2 \%)$ & $287(4 \%)$ & $650(7 \%)$ & $362(8 \%)$ \\
\hline $60-79 \%$ & $1035(1 \%)$ & $218(3 \%)$ & $561(6 \%)$ & $267(6 \%)$ \\
\hline $80-100 \%$ & $3984(6 \%)$ & $701(10 \%)$ & $2435(26 \%)$ & $1168(27 \%)$ \\
\hline $\begin{array}{l}\text { Young children }(<3 y) \text { in the } \mathrm{HH} \\
(\mathrm{t}-1)\end{array}$ & $39,844(55 \%)$ & $3754(55 \%)$ & $6782(72 \%)$ & $2292(53 \%)$ \\
\hline Married couple & $34,978(48 \%)$ & $3338(49 \%)$ & $7014(74 \%)$ & $3422(80 \%)$ \\
\hline \multicolumn{5}{|l|}{ Mean age $(\mathrm{t}-1)$} \\
\hline Man & 36.7 & 36.3 & 33.2 & 33.2 \\
\hline Woman & 34.6 & 34.2 & 30.2 & 30.9 \\
\hline \multicolumn{5}{|l|}{ Region } \\
\hline Flanders & $43,938(61 \%)$ & $1186(17 \%)$ & $2840(30 \%)$ & $2033(47 \%)$ \\
\hline Brussels Capital Region & $3418(5 \%)$ & $792(12 \%)$ & $4554(48 \%)$ & $1108(26 \%)$ \\
\hline Wallonia & $24,984(34 \%)$ & $4812(71 \%)$ & $2026(22 \%)$ & $1161(27 \%)$ \\
\hline
\end{tabular}


integration as more couples are of a mixed nature, compared to the Turkish couples. Nevertheless, the amount of mixed couples is less than half that of the Southern European couples.

When considering the financial background of the former couples, we observe high levels of dual earner couples before the break-up. Only in the Moroccan and Turkish community, we see more single breadwinner models both of a male and a female kind. In one fifth of the couples, the woman earns more than $80 \%$ of the income. On the other hand, the dependency on welfare state transfers is much higher in these latter communities. This confirms the economic weaker position of Moroccan and Turkish households, which was already clear from Fig. 9.2. The Moroccan couples are slightly younger which might also explain the higher share of young children (below 3 years) in these couples. As shown in Table 9.1, almost half of all couples had young children in their households before the relationship dissolution. The regional distribution of Belgian couples follows the national population figures with about two thirds of Flemish couples and one third of French speaking couples. The other groups do not follow this pattern with Southern European couples living more in the Southern part of the country and Moroccan and Turkish couples living relatively more in the Capital region of Brussels. Lastly, we also have more married couples in the Turkish and Moroccan community. Even though we aimed for an equal division of married and cohabiting couples (which succeeded in the Belgian population), the number of cohabitations among Turks and Moroccans was too low to obtain equal shares of both types of relationships in this study.

\subsubsection{Multivariate}

Our descriptive results demonstrate that the financial drop in income is considerable for women across all groups but with clear observable differences within the female respondents. The differences with men (not shown in Fig. 9.2) are considerable and therefore, we decided to estimate all models separately for men and women. The null random intercept model (Table 9.2) disentangles the total variance in adjusted household income in a within-group (within individuals, over time) and a betweengroup variance component (between individuals). As shown in Table 9.2, the variance decomposition in all eight groups differs to a considerable degree. For Belgian $(63 \%(0.48 / 0.28+0.48))$ and Southern European men $(62 \%)$, a large proportion of the variance in the model is due to differences between individuals. For Moroccan (49\%) and Turkish (47\%) men, more differences are found in the income trajectory over time. Among women, the same pattern is found, even though at a lower level. Within each group, women show fewer differences between individuals than over time.

When looking at the parameters in Table 9.2, we observe clear differences in overall intercept indicating lower income levels among Moroccan and Turkish men and women, compared to the other two groups. All individuals also show a gradual increase in income (pre-split growth) before the break-up. This is due to promotions 


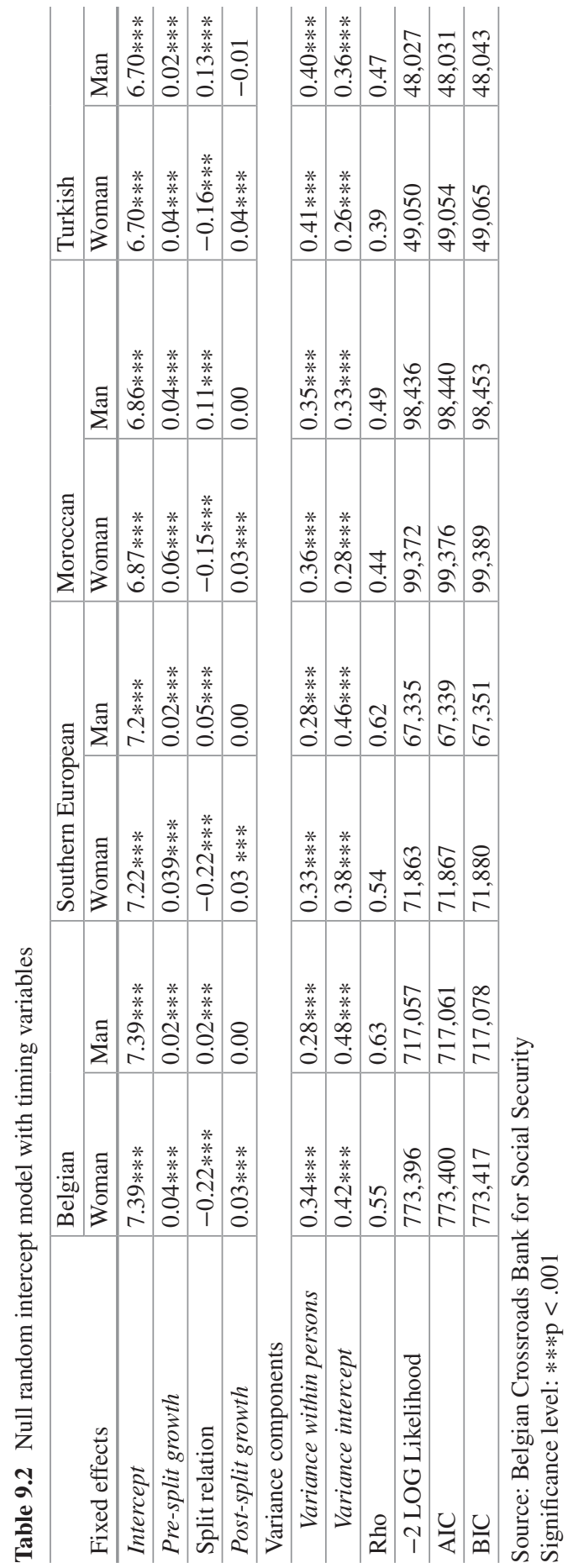


or upward job mobility. Among all women, a significant drop in income is revealed by the "split relation" parameters. The year of the break-up, all women see their income decline. The loss of income however is larger for the strong, wealthier groups (Bel: -0.22 ; SEU: -0.22 ) compared to the economically weaker women (Mor: -0.15; Tur: -0.16). For men, the change in income is significant and positive. This shows the relative financial gain of men when breaking up a family. A reversed pattern is visible across all four groups with economically weaker men (Mor, Tur) showing higher financial gains than the higher income groups (Bel, Seu). At the same time, this gain income for men is accompanied with a non-significant income growth after the divorce. This implies that the male income does not increase above the gain they experienced with the break-up. Possibly, this has to do with the absence of any incentive to cope with the financial consequences of the break-up. This is different for women where we observe a positive and significant post-split income growth. There are no differences between the four groups. All growth parameters are around 0.03 in size (and highly significant).

The main purpose of the null random intercept model is to decompose the variance in the models and to look at the general estimated income trajectory. We can conclude from Table 9.2 that the earlier observed gender gap is visible in this sample across all groups: women lose financially when the household dissolves and men gain. In Table 9.3, we expand our analysis with more detail to the composition of the migrant groups in our sample. The reference category in Table 9.3 is a homogenous couple with two partners from the same generation (2nd or 3rd or a combination of 2 nd and 3rd). We look at both homogenous couples in which either the man of the woman is a first generation migrant, and to mixed couples in which either the man or the woman is from the group at stake (Seu, Mor, Tur). In the model, the composition of the couple is adopted as a main effect but also interaction effects with timing variables (split and post-growth) are included. These interaction effects enable us to see whether the overall financial trajectory (as described in Table 9.2) is different for these couples. As we are not interested in income trajectories, independent from life course events, we did not include interaction effects with the prebreak income trajectory.

The main effects of couple composition indicate that mixed relationships are not different from homogenous later generation couples. As these mixed couples are also not significantly different from later generation respondents, we can assume that the combination of backgrounds itself plays no role in post break-up dynamics. This is only weakly supported. Only in the Moroccan and to a lesser degree the Turkish community, couples with a migrating partner have different income trajectories. Moroccan and Turkish male income trajectories are lower $(-0.12 /-0.13)$ when they have a migrating partner (and vice versa among the women: 0.09/0.02). When the couple has a migrating man, results are less conclusive. We see a higher income for male Turkish migrants (0.09) and a lower income for second generation Moroccan women (-0.09).

The influences of couple composition on the trajectories over time are rather limited. Again, only effects are found on the income change at the moment of the break-up (split relation) in homogenous couples with a migrating partner. For 


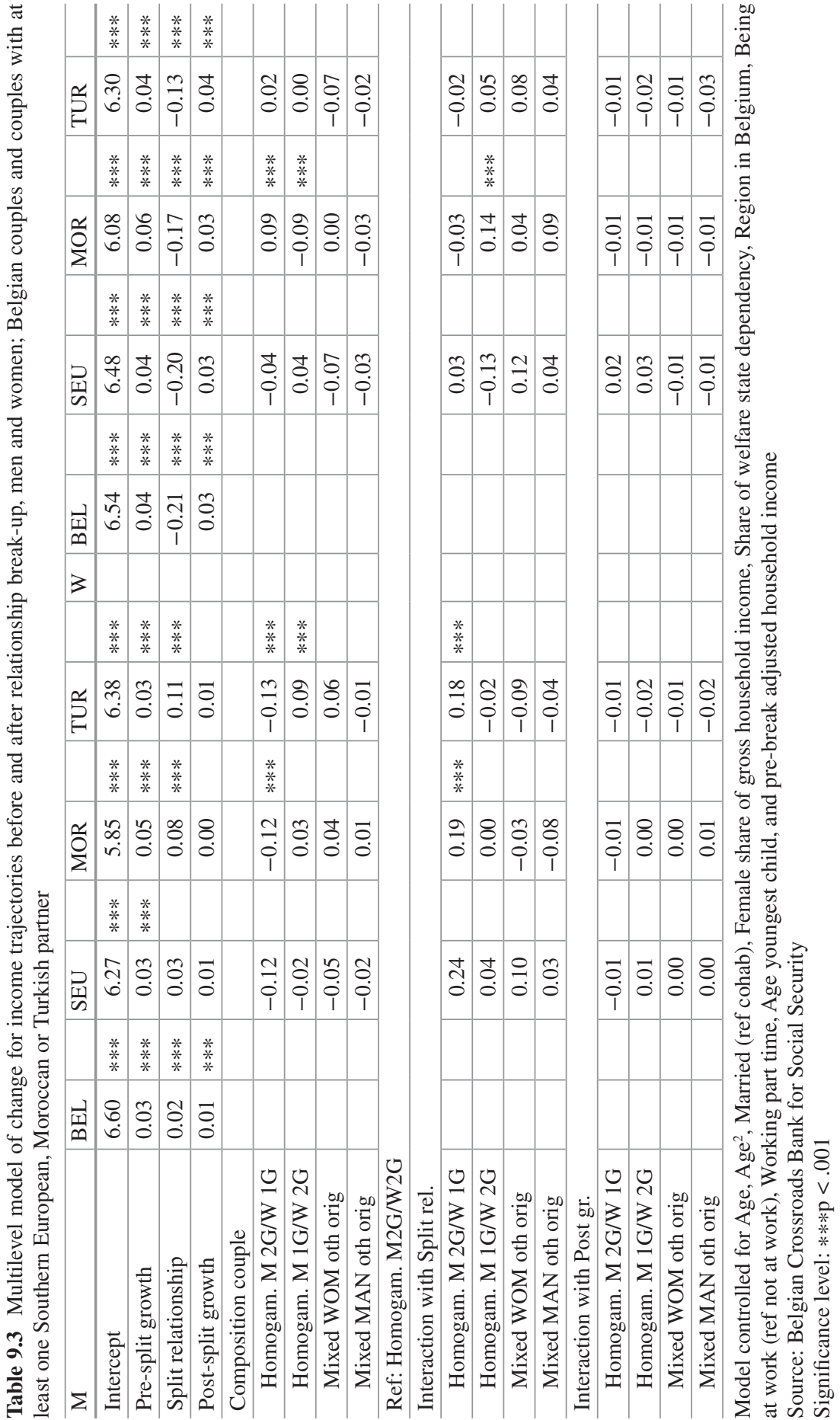


Moroccan and Turkish men with a migrating partner, the overall income growth at the break-up (Mor: 0.08; Tur: 0.11) increases sharply when their partner leaves the household. For Moroccan men, the gain in income by splitting up is $0.27(0.08+0.19)$ and for Turkish men $0.29(0.11+0.18)$. For women who have a migrating partner, the income fall when breaking up is softened. For Moroccan women with a migrating partner, the initial income drop of -0.17 , is reduced to $0.03(-0.17+0.14)$. For Turkish women, we see the same effect though non-significant. Their income drop is reduced from -0.13 to $-0.08(-0.13+0.05)$. The changes in post-split growth are all non-significant. That means that the initial recovery trajectories after the break-up remain identical when controlled for couple composition.

In the next step of the analysis, we examined differences in the effectiveness of strategies for moderating the economic consequences of union dissolution for divorced and formerly cohabiting men and women. Again, we introduced the main effects of three coping mechanisms (increasing one's work hours, repartnering and living with a parent). Furthermore, we interacted the coping strategies with the postgrowth timing variables. Interacting the strategies with the split variables turned out to be non-significant for all effects (due to the fact that the coping strategies are usually applied after the break-up).

A first striking result concerns the effects of composition of the couples that were discussed previously. When controlling for coping strategies, all compositional effects of couples disappear. In order to maintain the comparability with Table 9.3, we decided to keep these effects in the model. The main effects of the three coping strategies show that increasing one's work does not significantly influence the overall income trajectory. This is counterintuitive since increasing work hours implies more income. Repartnering does increase the income, especially among the women. Having a parent in the home gives mixed results but shows a decrease in income for men and women. Especially in Moroccan and Turkish former families the switch to the parental home has a large impact in the models. Since first generation migrants are generally unable to move back in with parents, these results mainly reflect the effect of moving into the parental home for second and later generation migrants. Finally the results for repartnering show that a new partner is beneficial for women. Across all four groups, large and significant increases are found of a beneficial effect on women's income trajectory.

When interacting the coping strategies with the post-growth income trajectory, we find a positive effect of increasing one's labour market attachment but only among Belgian men and women. When parents become involved, only Belgian and Southern European men experience a negative pressure on their post break-up trajectory. The significant main effects among Moroccan and Turkish men and women are not reinforced, nor hindered in an interaction with the post growth trajectory. Finally, we see overall negative interaction terms of repartnering on income growth across all four groups and for both genders. For men, this means that the nonexisting effect of repartnering implies that the new partner negatively influences their income trajectory over time. For women, we found large positive main effects on the general income level which seem to be tempered by a lowering post-growth trajectory of income after the break-up. The positive main effects however by far 
outweigh the negative compensation effects in the interaction with the postgrowth term.

In order to limit the size of the tables, we did not include the parameters of our control variables. All control variables behaved in the expected direction. The models in Table 9.4 show a positive effect for age (older people have higher incomes). Married men have a lower income than cohabiting men. For women, this effect is only found among Moroccan and Turkish couples. Belgian and Southern European married women show no differences with cohabiters. A higher share of the woman's income in the gross household income decreases the overall income of men, an effect not found among the women. Welfare dependence is proxy for economic deprivation as all groups and both genders show significant lower income trajectories when the family is more dependent on welfare state transfers. Region in Belgium does have no effect on the income trajectory and having young children in the household increases the income level (due to child care benefits). Also labour market attachment gives the expected results with being at work having a positive effect on the overall income and working part-time showing negative effects. The overall adjusted household income before the break also positively influences the income trajectory of the former partners.

\subsection{Discussion}

In this study we extended our previous studies on the economic consequences of divorce (de Regt et al. 2012; Jansen et al. 2009) to a sample that contains sufficient heterogeneity on backgrounds in terms of country of birth and nationality. We asked if migration background plays a role in coping with financial consequences after a relation break-up.

We started our analytical journey with a general hypothesis, already tested in our earlier work: is the income trajectory different for men and women? As expected, we (again) find that women suffer more severe financial losses after a break-up than men. The adjusted household income drops significantly across all female groups in our sample. For men, we see a non-significant drop or even an increase in adjusted household income. This overall result proves that, despite the evolution in Belgium from a single breadwinner model to a dual earner model, the outcomes of life course events are still gendered.

The next step in the analysis was to focus on the financial consequences of former partners, according to their migrant background. Because ex-partners with a migrant background face more severe economic circumstances, we hypothesized that this economic weaker position would entail a 'penalty' when the household would dissolve (hypothesis 3a). This hypothesis was not confirmed. Ex-partners with a migrant background do not experience immediate stronger financial consequences. Probably, the very fact that they start off from a more disadvantaged socioeconomic position could explain the smaller drop in income afterwards: if you have less, you lose less. Therefore, we find that both Belgian and Southern European 


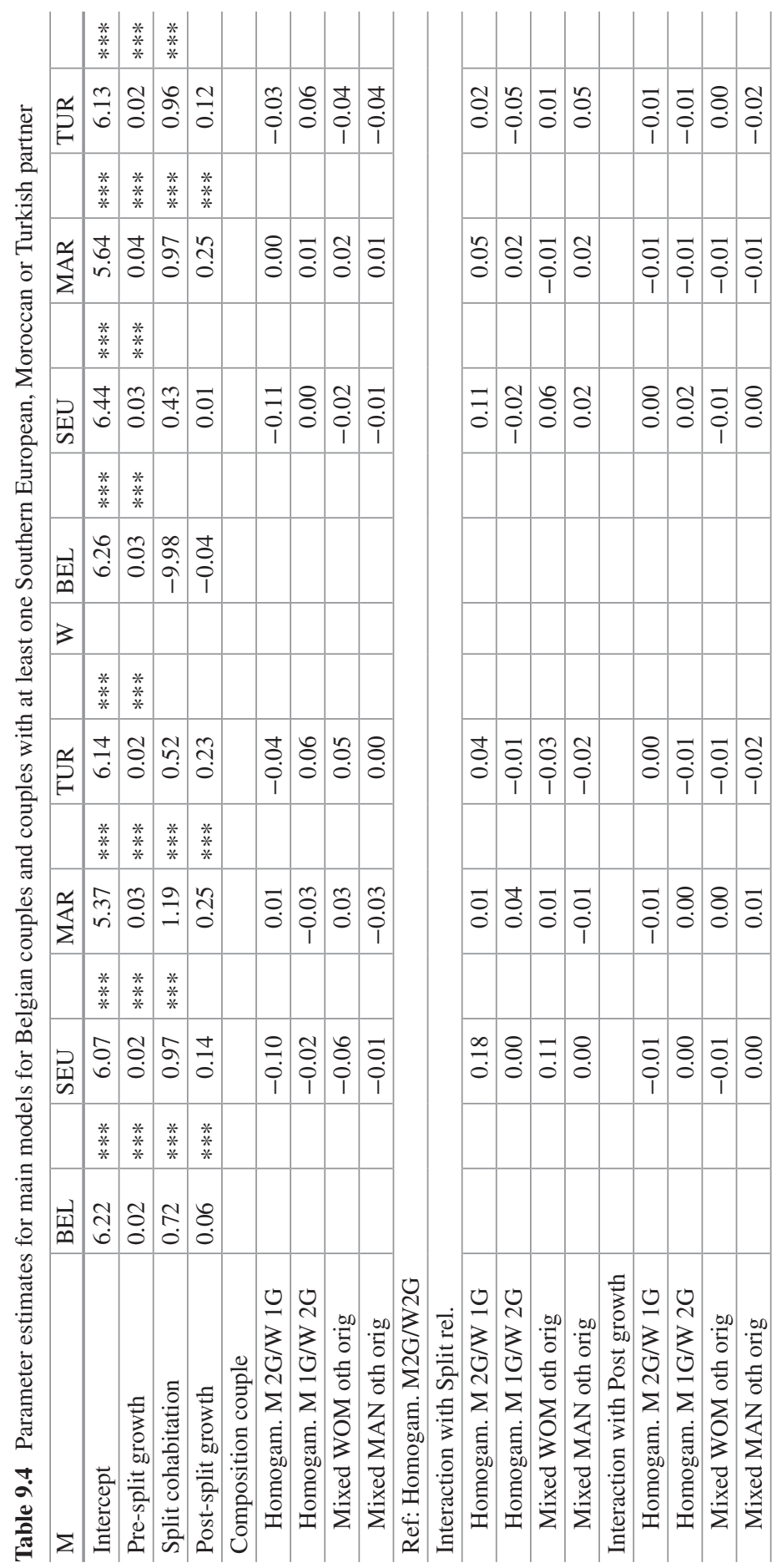




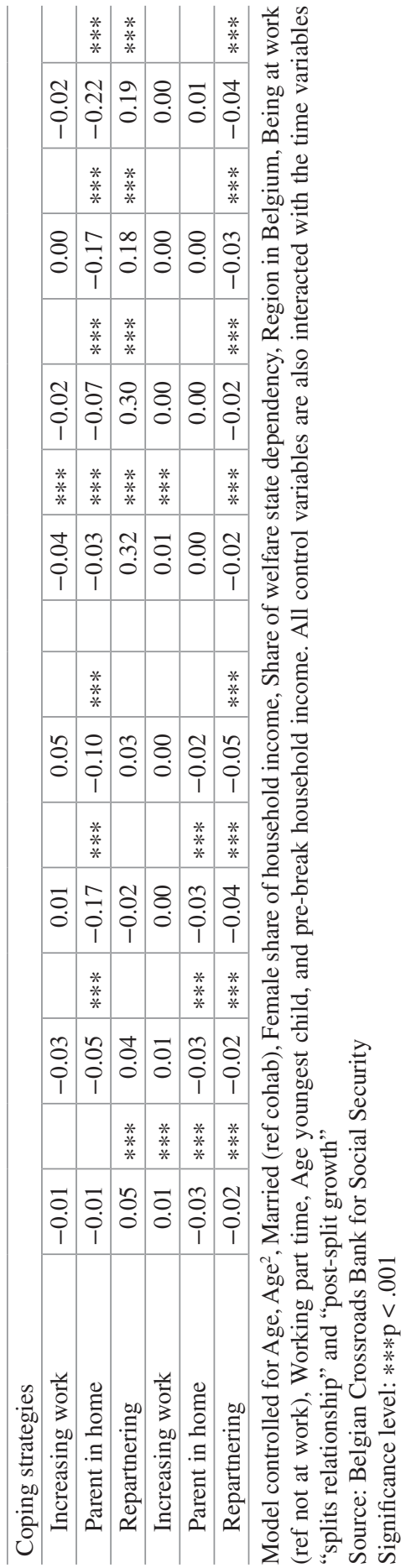


women (both stronger economic groups) lose more compared to Turkish and Moroccan women. When extending this analysis to the composition of the couple, we expected that the migration history would also matter in this respect. We hypothesised that men and women of the first generation who migrated in the context of marriage migration would face more detrimental losses compared to later generation couples or mixed couple (hypothesis 3b). Also this hypothesis was not confirmed: first generation men and women do not experience stronger losses. Again the argument that having a lower income makes you lose less applies. However, their second generation partner (the partner that married a man or woman from the country of origin) experiences markedly weaker financial consequences compared to partners that did not marry a first generation migrant. The financial gains of union dissolution for Turkish and Moroccan men that married a first generation partner are larger compared to Turkish and Moroccan men that had a partner from the same generation. The losses from union dissolution for Moroccan women who married a first generation man were also more limited compared to Moroccan women that were partnered with a partner from the same generation. Hence, these results indicate that union dissolution is more beneficial for partners that were in a union with a partner in a particularly vulnerable socio-economic position. The fact that the first generation partner in a couple formed by marriage migration does not experience stronger financial losses could possibly be explained by the financial support they receive from the migrant community.

Comparable to the drop in income, our hypotheses on the post-dissolution income trajectory (hypotheses $4 \mathrm{a}$ and $4 \mathrm{~b}$ ) are also not confirmed. The post-split growth is similar for all migrant couples irrespective of migrant background. These results indicate that, even though migrant populations are characterised by a weaker socio-economic position and specific community dynamics, these differences do not impact the financial recovery from union dissolution. When regarding couple composition, we also do not find any differences in post-divorce growth. It seems that the stronger partner in a mixed 1st and later generation household does not significantly profit from the exit of the economically weaker first generation partner in terms of post-dissolution income growth.

The analysis of the financial trajectory after a break-up was the first step in our analysis. The second research question in this chapter concerns the coping strategies of former partners after the break-up. In what way do people try to cope with the financial loss of income due to their break-up. We identified and tested three possible coping strategies: increasing employment, repartnering and returning to the parental home. Each time, we first tested a general hypothesis irrespective of migration background $(\mathrm{H} 2 \mathrm{a}, \mathrm{b}, \mathrm{c})$ and next we tested the same hypotheses again but focussed specifically on the migration background of the former partners (H5a,b,c).

Our results show that increasing one's employment is an effective coping strategy and significantly improves the post break-up income trajectory for former partners (Hypothesis 2a). But labour market strategies are clearly influenced by the background of the former spouses. We see that Belgian men and women are benefitting more from this strategy while the same results are not found among men and women with a migrant background (Hypothesis 5a). Given that men and women with a migrant background are more often found in unstable employment and jobs 
characterized by lower wages and short-term contracts, increasing one's employment may not be an effective way to help post break-up financial recovery. It is striking that the Southern European men and women are also not benefitting from this strategy as they are better off economically compared to the Moroccan and Turkish men and women.

When a former spouse starts living together with a new partner (whether married or unmarried) we expected an increase in the financial position for women and a decrease for men (hypothesis $2 b$ ). This general effect is found in our data and it confirms the weaker income position of women who make men's adjusted household income decrease when moving in while her adjusted income increases. When looking at migration background, we see that the effects of women go in the expected direction with an increase across all groups in women's relative income. Hypothesis $5 \mathrm{~b}$ is also confirmed as we find no differences across our four groups. For men, we find no effect on the general income trajectory (main effect) but we do find a negative post-income trajectory. Since the overall effect is negative, we also consider hypothesis $5 \mathrm{~b}$ for men to be confirmed.

A last possibility for former partners is to return to the parental home (sometimes called the boomerang strategy). When considering this strategy, we expected a positive overall effect (hypothesis 2c) with more limited gains among migrant groups (hypothesis 5c). Regarding the overall effect, our hypothesis is not confirmed. Instead of a positive effect, we found a negative effect of the boomerang strategy: living again with one's parents lowers the adjusted household income for all groups. With respect to migrant groups, our hypothesis is confirmed since the negative effects are especially strong among Turkish and Moroccan men and women. The assumption behind our hypothesized positive overall effect was that parents are able to support the ex-partners because they provide a (financially) stable environment. A possible explanation of the consistent opposite effects is that moving in with parents is more common among men and women who are in a very vulnerable socioeconomic position. If their parents are also characterized by a more vulnerable position such as unemployment, unstable labour market attachment or low wages, this implies a financial setback when the income then has to be divided between more household members. Given the economically precarious position of immigrants and their children in Belgium, it makes sense that the strategy of moving in with parents is less efficient for ex-partners with a migrant background. Since the capability of moving back in with parents is very limited for first generation migrants, the effect for migrant groups most likely reflects the efficiency of moving back in with parents as a coping strategy for second or later generation migrants.

\subsection{Conclusion}

In this chapter, we extended previous studies on the financial consequences of divorce and separation with a focus on migration background. Previous studies have always assumed a homogeneity in the background of former partners while focus- 
sing on gender effects. While keeping the gender perspective, we extend this literature by taking migration background and migration history into account.

The results show that financial consequences still show a highly gendered pattern with men gaining (in relative terms) from the break-up and women losing income. We also found differences according to migration background but not in the direction we expected. Weaker economic migrant groups such as Moroccan and Turkish men and women experience a lower financial drop in income compared to stronger groups (Belgian and Southern European). Only within the migration population, couples with a 1st generation partner show significant differences in economic consequences. Especially the former partner of a first generation migrant is better off after the break-up.

The relative positive outcome among economically weaker groups could stem from two sources. On the one hand, the generous Belgian welfare provisions might succeed in protecting these former partners and keep them out of poverty. On the other hand, the small drop in income might be less reassuring than a regression parameter might seem to suggest. When in an economic weak position any fall in income, even the slightest one, might result in ending up in poverty or aggravating an already existent poverty situation. As such, the advantaged comparison with stronger Belgian and Southern European groups could blur the daily difficulties among these Moroccan and Turkish men and women.

When considering coping strategies, all effects concerning labour market position and repartnering turned out as expected. Only the return to the parental home showed a negative outcome instead of the expected gain in relative income position. Again, the economic background of migrant families explains, to a large extent, the direction of these effects. When working in an economic frail and uncertain situation, increasing one's working hours or changing jobs is not a guarantee on a better income position. In some cases, increasing working hours could imply losing one's benefits which lowers instead of increases the total household income. Also the boomerang strategy of returning to the parental home is no guarantee to economic gains. When your parents are also in a weak financial position, increasing the total number of household members and dividing the scarce income among them results in a worse situation. Of course, we are aware that this chapter only looks at the financial position of the household. Returning to the parental home has other benefits to the former partner. The parental household gives social support and warmth or could also provide child care. This could help the former partner in continuing to work and recovering financially on the long term even though in the short term our models show a decrease in income.

Our study has some inevitable limitations. First, the composition of the households made us make choices to place individuals in certain families while leaving them out in other categories (e.g. the mixed couples). As a consequence, we could include between-group differences in our analyses. Groups are compared across models but not in a formal statistical manner due to this potential overlap across couples. Second, we only consider the coping strategy of increasing one's labour supply as an increase compared to the year previous to the break-up. This implies that we ignore potential anticipation effects as ex-partners (predominantly women) 
might increase their labour market attachment longer before the actual break-up (Poortman 2005; Thielemans and Mortelmans 2017). Third and most importantly, the register data did not allow us to control for educational attainment or job status. Since these are crucial components of one's SES, this is an important blind spot in our analyses. Even though the registers do give us an impressive statistical power, missing these indicators is a considerable handicap.

Given our ever diversifying society characterised by globalisation, geographical mobility and inter-ethnic relationships, considering migration background in family studies grows in importance. As our societies diversify, we need to grasp the mechanisms behind the social and economic behaviour of people with a migrant background. As others have shown, these groups are characterised by a distinct combination of attitudes toward gender roles and family transitions, socioeconomic opportunities and links to the communities of residence and origin. Taking migrant background into account when uncovering causes and consequences of union dissolution helps us gain insight in the specific cultural and economic mechanisms underlying relationship break-ups. In this chapter, we have shown that the heterogeneity in economic power is crucial when studying processes of financial loss and recovery. Migrant background in itself is often not at the core of how income trajectories evolve but their economic background does play a crucial part in the explanatory models we have tested. In addition, we showed how migration generations and their parental homes have a differing influence in how people with a migrant background see their income after a break-up evolve. This complex interplay of coping mechanisms are important lessons for academics but also for policy makers focussing on life course events and economic frailty or poverty.

Acknowledgement This chapter benefited from the support of the Centre for Population, Family and Health $(\mathrm{CPFH})$ at the University of Antwerp and the Flemish Agency of Innovation and Entrepreneurship (Grant number:140069), which enabled Open Access to this chapter.

\section{References}

Andreß, H.-J., Borgloh, B., Bröckel, M., Giesselmann, M., \& Hummelsheim, D. (2006). The economic consequences of partnership dissolution-A comparative analysis of panel studies from Belgium, Germany, Great Britain, Italy, and Sweden. European Sociological Review, 22(5), 533-560. https://doi.org/10.1093/esr/jc1012.

Baert, S., Heiland, F., \& Korenman, S. (2016). Native-immigrant gaps in educational and schoolto-work transitions in the 2nd generation: The role of gender and ethnicity. De Economist (0013-063X), 164(2), 159-186. https://doi.org/10.1007/s10645-016-9273-4.

Boyd, M. (1989). Family and personal networks in international migration: Recent developments and new agendas. International Migration Review, 23, 638-670. https://doi. org/10.2307/2546433.

Carpentier, S., Neels, K., \& Van den Bosch, K. (2014). How do exit rates from social assistance benefit in Belgium vary with individual and local agency characteristics? Safety nets and benefit dependence (pp. 151-187). Bingley: Emerald Group Publishing Limited. 
Corijn, M., \& Lodewijckx, E. (2009). De start van de gezinsvorming bij de Turkse en Marokkaanse tweede generatie in het Vlaamse Gewest een analyse op basis van Rijksregistergegevens. Brussel: Studiedienst van de Vlaamse Regering.

Corluy, V., Haemels, J., Marx, I., \& Verbist, G. (2015). The labour market position of secondgeneration immigrants in Belgium (NBB Working Paper No. 285).

Couch, K. A., Tamborini, C. R., Reznik, G. L., \& Phillips, J. W. (2013). Divorce, women's earnings, and retirement over the life course. In Lifecycle events and their consequences: Job loss, family change, and declines in health (pp. 133-157). Stanford: Stanford University Press.

De Haas, H. (2010). The internal dynamics of migration processes: A theoretical inquiry. Journal of Ethnic and Migration Studies, 36(10), 1587-1617.

de Regt, S., Mortelmans, D., \& Marynissen, T. (2012). Financial consequences of relationship dissolution : A longitudinal comparison of formerly married and unmarried cohabiting men and women. Sociology : The Journal of the British Sociological Association, 47(1), 90-108. https:// doi.org/10.1177/0038038512453793.

Dupont, E., Van Pottelberge, A., Van de Putte, B., Lievens, J., \& Caestecker, F. (2017). Partner choices in long established migrant communities in Belgium. Historical Life Course Studies, $4,20-40$.

Fernandez, R., \& Fogli, A. (2009). Culture: An empirical investigation of beliefs, work, and fertility. American Economic Journal: Macroeconomics, 1(1), 146-177.

Fisher, H., \& Low, H. (2009). Who wins, who loses and who recovers from divorce? In Sharing lives, dividing assets: An inter-disciplinary study (pp. 227-256). Oxford, Hart Publishing.

Förster, M. F. (2007). What are equivalence scales? Retrieved from http://www.oecd.org/eco/ growth/OECD-Note-EquivalenceScales.pdf

Furtado, D., Marcén, M., \& Sevilla, A. (2013). Does culture affect divorce? Evidence from European immigrants in the United States. Demography, 50(3), 1013-1038.

Gardiner, K., \& Millar, J. (2006). How low-paid employees avoid poverty: An analysis by family type and household structure. Journal of Social Policy, 35(3), 351-369.

Heath, A. F., Rothon, C., \& Kilpi, E. (2008). The second generation in Western Europe: Education, unemployment, and occupational attainment. Annual Review of Sociology, 34, 211-235. https://doi.org/10.1146/annurev.soc.34.040507.134728.

Herbst, A., \& Kaplan, A. (2016). Mothers' postdivorce earnings in the context of welfare policy change. International Journal of Social Welfare, 25, 222-234.

Hernández-Plaza, S., Alonso-Morillejo, E., \& Pozo-Muñoz, C. (2006). Social support interventions in migrant populations. British Journal of Social Work, 36(7), 1151-1169. https://doi. org/10.1093/bjsw/bch396.

Hox, J. J. (2002). Multilevel analysis. Techniques and applications. Mahwah: Lawrence Erlbaum Associates.

Jansen, M., Mortelmans, D., \& Snoeckx, L. (2009). Repartnering and (re)employment: Strategies to cope with the economic consequences of partnership dissolution. Journal of Marriage and Family, 71(5), 1271-1293. https://doi.org/10.1111/j.1741-3737.2009.00668.x.

Jarvis, S., \& Jenkins, S. P. (1999). Marital splits and income changes: Evidence from the British household panel survey. Population Studies, 53(2), 237-254. https://doi. org/10.1080/00324720308077.

Kleinepier, T., Berrington, A., \& Stoeldraijer, L. (2017). Ethnic differences in returning home: Explanations from a life course perspective. Journal of Marriage and Family, 79(4), 10231040. https://doi.org/10.1111/jomf.12399.

Koelet, S., Corijn, M., Lodewijckx, E., Mortelmans, D., d'Hooge, A., \& Hermans, P. (2009a). Echtscheiding bij personen van Turkse en Marokkaanse herkomst Deel 2: Kwantitatieve en kwalitatieve studie. Antwerpen: Steunpunt Gelijkansenbeleid.

Koelet, S., Hermans, P., Torfs, N., Vanvoorden, K., \& Timmerman, C. (2009b). Echtscheiding bij personen van Turkse en Marokkaanse herkomst Deel 1: Literatuurstudie. Antwerpen/Hasselt: Steunpunt Gelijkekansenbeleid. 
Lievens, J. (1999). Family-forming migration from Turkey and Morocco to Belgium: The demand for marriage partners from the countries of origin. International Migration Review, 33(3), 717744. https://doi.org/10.2307/2547532.

McManus, P. A., \& DiPrete, T. A. (2001). Losers and winners: The financial consequences of separation and divorce for men. American Sociological Review, 66(2), 246-268.

Münz, R. (2007). Migration, labor markets, and integration of migrants: An overview for Europe. HWWI Policy Paper, 3-6.

Mussche, N., Corluy, V., \& Marx, I. (2014). Migrant access to social security-policy and practice in Belgium. Antwerp: Antwerp University-Centre for Social Policy Herman Deleeck.

Phalet, K. (2007). Down and out: The children of immigrant workers in the Belgian labour market. In A. F. Heath \& S. Y. Cheung (Eds.), Unequal chances: Ethnic minorities in Western labour markets (pp. 142-180). Oxford: Oxford University Press.

Poortman, A.-R. (2005). Women's work and divorce: A matter of anticipation? A research note. European Sociological Review, 21(3), 301-309. https://doi.org/10.1093/esr/jci019.

Shirahase, S., \& Raymo, J. M. (2014). Single mothers and poverty in Japan: The role of intergenerational coresidence. Social Forces, 93(2), 545-569.

Singer, J., \& Willett, J. (2003). Applied longitudinal data analysis. Modeling change and event occurrence. New York: Oxford University Press.

Stiglbauer, B., \& Batinic, B. (2012). The role of Jahoda's latent and financial benefits for work involvement: A longitudinal study. Journal of Vocational Behavior, 81(2), 259-268.

Thielemans, G., \& Mortelmans, D. (2017). Anticipating divorce: Is knowing half the battle?. Paper presented at the 15th meeting of the European network for the sociological and demographic study of divorce. Antwerp, Belgium, 5th-7th October 2017.

van Damme, M. (2010). Hoe vrouwen hun eigen boontjes doppen. Tijdschrift voor Genderstudies, 13(4), 48-61.

van Damme, M., Kalmijn, M., \& Uunk, W. (2009). The employment of separated women. The impact of individual and institutional factors. European Sociological Review, 25(2), 183-197. https://doi.org/10.1093/esr/jcn042.

Open Access This chapter is licensed under the terms of the Creative Commons Attribution 4.0 International License (http://creativecommons.org/licenses/by/4.0/), which permits use, sharing, adaptation, distribution and reproduction in any medium or format, as long as you give appropriate credit to the original author(s) and the source, provide a link to the Creative Commons license and indicate if changes were made.

The images or other third party material in this chapter are included in the chapter's Creative Commons license, unless indicated otherwise in a credit line to the material. If material is not included in the chapter's Creative Commons license and your intended use is not permitted by statutory regulation or exceeds the permitted use, you will need to obtain permission directly from the copyright holder.

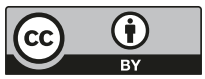

